\title{
The Mohajir Identity in Pakistan: The Natives' Perspective
}

\author{
Fouzia Rehman Khan ${ }^{1} \&$ Fehmida Manzoor ${ }^{1}$ \\ ${ }^{1}$ Sardar Bahadur Khan Women's University, Quetta, Pakistan \\ Correspondence: Fouzia Rehman Khan, Department of English, Sardar Bahadur Khan Women's University, \\ Quetta, Pakistan. Tel: 92-333-786-6702. E-mail: fozia.wu@gmail.com
}

$\begin{aligned} & \text { Received: January 1,2018 Accepted: February 7, } 2018 \quad \text { Online Published: March 17, } 2018 \\ & \text { doi:10.5539/ijel.v8n4p14 }\end{aligned}$ URL: https://doi.org/10.5539/ijel.v8n4p14

\begin{abstract}
Analysing narratives as a site of identity constructions and negotiation is an expanding genre in the field of linguistics. The present study explores the Mohajir identity of Urdu Speaking in Pakistan through the narratives of the natives. This research is a qualitative analysis of the narratives that are formed through the semi structured private interviews of Urdu Speaking Mohajir/ immigrants in Pakistan. The interpretive analysis of the interviews reflected the subjective reception of the discursive practices, which were found to be negative and the term "Mohajir" was declared to have an undesirable connotation with the associated discourses having a similar impact. The study recommends that the word "Mohajir" should be excluded from the everyday discourse. There is a need for avoidance of the racist, exclusionary and discriminatory discourses and discursive practices because such discourses eventually become public and generate anti-immigrant sentiments. At the same time discourses of unification should be promoted so as to establish harmonious discursive practices for a peaceful coexistence of different ethnic and linguistic groups living in Pakistan.
\end{abstract}

Keywords: narratives, identity, immigrants, Mohajir

\section{Introduction}

Defined by the census of Pakistan, 1951, "A Mohajir is a person who has moved into Pakistan as a result of partition or for the fear of disturbances connected therewith". The history witnessed an unprecedented movement of 8 million people who migrated to Pakistan (Refugee Review Tribunal, 2008). According to Raza (2005), the Mohajirs are considered as culturally displaced community of Islamic Republic of Pakistan. The question of Mohajir identity remains an unsolved political issue in Pakistan. The present study explores this Mohajir identity through the narratives of the natives. The study is significant because the focus of related literature has moved from structuralist perspective to the role of narrative in the identity construction and performance in interaction (Farrell, 2008). The data collected in the form of narratives for this study as a discursive form is important as it assembles and organizes the narrator's concept of himself.

In Urdu, the term Mohajir explicitly refers to an emigrant or refugee whose decision to leave the homeland is directly related to the preservation of his/her faith. A Mohajir refers to one who has performed the act of "hijrat"; this word also comes from Arabic and connotes "separation, migration, flight, specifically the flight of the prophet Mohammad from Mecca to Madina" (Mohajir, 1998, p. 813). It therefore means that hijrat is not the usual kind of migration but an exalted one that comes with a complete historical and a religious background and implies sacrifice of one's land, property and even relatives for the sake of one's faith- this therefore becomes a defining characteristic of Mohajir identity. Hijrat differs from other migration for its purity of purpose and like other migrations it comes at a heavy cost of uprooting people physically making them estranged to the new culture.

At the time of partition of Indo-Pak subcontinent the newly formed state of Pakistan used this word for the people coming from India and in a way bestowed holiness on them, making an obligation on the locals to be good hosts. Interestingly, a majority of the total immigrants who migrated from the East Punjab to the West Punjab, a part of Pakistan, stopped calling themselves and were not called by others as Mohajirs because they assimilated quite quickly on account of their shared language and culture. The term Mohajir remained tagged with immigrants who came from the north, west and central provinces of India. These immigrants were in minority in the total post-partition migration. The Mohajirs settled in Sindh but their case was too different from those migrated and later assimilated in Punjab. They remained unassimilated in Sindh. In the beginning days of 
Pakistan Mohajirs called themselves Pakistanis because they were proud of the successful struggle they did for Pakistan. Taking up the identity as "Pakistani" and not as Mohajir any longer, justified their settling in Urban Sindh and even dominating the state structure (Baig, 2005). The Mohajir as a term remained dormant till it was politically revived by the emergence of Mohajir Qomee Movement (MQM) in 1984. Altaf Hussain the founder of MQM tried to bring in unity with the term Mohajir among the Urdu speakers who were mostly settled in the urban Sindh, concentrated in the three cities of Karachi, Hyderabad and Sukker. Henceforth, Mohajir did not refer to all those people who migrated from India but the word represented a linguistic identity. "Hence, Mohajir ethnicity became synonymous with the new political identity of the descendants of Urdu speaking Indian migrants who settled in Urban Sindh" (Baig, 2005, p. 8).

"Mohajirs" are also called Urdu Speaking. The term "Urdu Speaking" was coined because most of the people who migrated from the minority provinces of India and settled in Sindh spoke Urdu or some dialect of it as their mother tongue, though there were immigrants in good number from Gujrat and Bombay whose mother tongue was not Urdu, therefore this new identity formation was more a social construct than a natural one.

\section{Literature Review}

The current research in the narrative is quite diverse and covers the varied areas from discourses of national identity to family discourses of gender, divorce, and childbirth to learning of second language, language ownership to as wide a field as asylum seekers process. Thus immigrants can be part of the discourse of inclusion and exclusion according to the ongoing politics of the place (Koegan, 2008). For instance in the US, where after centuries explicit exclusion of immigrants on the basis of ethnic origin and race is prohibited through immigrant reforms, and a new inclusion-exclusion discourse has emerged.

Researchers who have worked with narratives and identities are convinced that there are vivid differences in narrations of people of different nationalities, ethnicities, and even gender. Studies cited in Finna (2003) are those conducted by Tannen (1980) who worked on the narrative of American and Israel and reported differences in topic selection, type of narrative and the frameworks. Different aspects of narratives have been worked on like strategies of narration and organization of narratives. Narratives position the narrator into certain roles, for instance, Schiffrim (1996) studied such positioning in the stories told by Jewish about their relations where they positioned themselves as women and members of the Jewish family.

Pozaic (2009) worked on immigrant identities in Canada by analyzing the popular Canadian narratives. He based his research on ethnography and conducted interviews of Columbians in Canada who lived in London Ontario. $\mathrm{He}$ found that Columbians formed their identity through the powerful hegemonic immigrant narratives. Through these narratives, it was shown that Columbians negotiate representation in the mainstream discourse and the self-representation, as they desire.

Weldeyesus (2007) tried to find out how narratives can be used as a vehicle in the construction of identity among Ethiopians living in the US. His focus was on the concept of Socialization and divided the concept into two as less socialization and more socialization depicted in the narratives as former self and current self. These were called as two identity positioning. The study tried to project more assimilated self, one that is linguistically and culturally fluent. These narratives fell under the genre of "immigrant narrative" as they contained experiences of the immigrants in terms of socialization in the mainstream life both linguistically and culturally.

Narratives of migration and settlement are the narrative in which almost by definition, a settled and stable sense of self is unsettled and challenged (Farell, 2008). Thus, they confront the discourse analyst and cultural theorist with the task of finding new ways of understanding traditional categories of identity and voice. In a growing body of literature on migration and identity, narratives are used as a meaning-making site of coherence for the negotiation and construction of identity and to understand self, which in such narratives are "destabilised and questioned" (p. 45).

Many theorists believe that the social construction of narrative and identity in relation to the immigrants is one of the best approaches to study immigration. Discourse certainly plays a role in identity politics. As Alaxander (2006, p. 65) says,

Discursive identity is contested. Political fights are, in part, about how to distribute actors across the structure of discourse, for there is no determined relation between any event or group on either side of the cultural schema. In periods of tension and crises, political struggle becomes of how far and to whom the discourses of liberty and repression apply (and) just how popular narratives of good and evil are applied.

It is difficult to define identity because of the complexity of the construct. In the simplest terms, it is a sense of belonging to the category. For Tajfel (1981) identity is a self-concept of a person, which he drives from living in 
a group or may be groups in addition to the emotional significance he gives to such a self-concept and his membership with that group. In this regard, the focus of some of the linguists has remained on the language, that language is an integral part of one's identity, which does not mean that identity is only linguistic or expressed only by language but language has a definite role in the construction of identity. Theorist working with discourse analysis explores the existence of fragmented and polyphonous identities within the same individual (Finna 2003), which changes and evolves according to the situation, context and interlocutors. Discourse analysts also explore how these created identities are imposed on interactions through social institutions.

According to Davis (1991), Identity as a concept sustains a certain kind of force that very few concepts carry and retain. Bhabha (1994) writes, "Identity is never a priori, nor a finished product; it is only ever the problematic process of access to an image of totality" (cited in Howard, 2000, p. 367). The totality that Bhabha talks about is difficult to achieve since identity is an ever-changing notion. Immigrants are nationals of some other country and being an immigrant itself is no identity and therefore these people pass through the problematic process in search of some identity. The process usually continues over generations but the image of totality is never achieved.

Findlay \& Li (1997) see migration as an act of identity. Migration can be a reason of change in ethnic identity. In many studies on immigrants, the media discourse is analyzed so as to explore their perception about themselves through such discourses. Sjorbery \& Rydin (2008) analyzed media discourse, making use of media ethnographic discursive approach. The study found important interconnections between the ongoing popular media discourse and the immigrants' perception of themselves, their culture and country and also how does the host country, in this case, Sweden looks at them. Findlay \& Li (1997) inform that migration studies attracted attention when the meaning of place changed with Poststructuralism. The place then started to be seen as an intersection of many social relations and migration as a process of identity change with the change in place. The development of such a context, increased interest in migration studies to study self, other and place in relation to migration. The social world of the migrants and potential migrants continues to be constructed throughout their lives. They transform it according to what they hear, discuss, and then assess. They in turn construct the image of race and place for other people through description of their experience and observation about the people and places that they come across.

Baker et al. (2008) studied migrant discourses through a combination of the discourse-historical approach and corpus linguistics. Verkaik (1994) conducted four months of ethnography on Mohajir identity and found that Mohajir describe themselves as modern, urban and middle class. Verkaik analysed the development and transformation of Mohajir identity from a group of people who strongly identified themselves with Pakistani national identity to a small segment of the society who define themselves as an ethnic community.

Researches on immigrant discourses have also been done through analysis of narratives. There is not much research regarding narratives and identity as Finna (2000) writes... aside from the mainstream images of who immigrants are, little research has been done on the identity that immigrants themselves build and project and on the processes that affect the formation of such identity (p. 132).

The formation of identity is a continuously unfolding process and therefore migrant identities might not be determined by their places. Researchers have used different methods to approach migrant identities such as biographies, life histories, and testimonies. The notion of "place" has been problematized in such researches on identity. The reworking of the place by the migrants has been emphasized in postcolonial migration studies, which is differently done by different communities. Thus a wide range of methodologies is continuously being employed to research migrants (Silvey \& Lawson, 1999). One of the popular ones is that of narratives which further consists of few paradigms. There are two distinguishable paradigms in narrative studies (Finna, 2003) since social construction became the focus of identity 1. Autobiography 2. Ethnomethodology. Much work on narratives is done taking the first tradition where self is the storyteller. Through this tradition relation between self and narrative can be worked out. The psychologist conducted such studies in the 70s and 80s. Scholars who have worked in this tradition were interested in finding out the relationship between the self and the narrative. Most of these scholars were the psychologists in the 70s and 80s. The later narrative studies grew on their methodology, exploring self-construction through narratives. Narrativization gives individual and groups a chance of making a sense of their experience with the provision of a temporal organization that makes the experience more coherent. It is only through narratives that any experience becomes shareable. The process of identity construction is seen as in a flux by the post-modernist where the self is constructed through reflection. Therefore the process is continuous and identities ever changing. This remains a consideration in autobiographical studies where inner reality is reflected through stories. In the autobiographical construction of the self, interaction is given quite an importance as it positions the storyteller and the audience but at the same time, many of the scholars have taken the process of constructing of self through narrator as monologic, as an 
expression of personal experience.

Personal experience narratives started with the work of Labov \& Waletzky (1976). In sociolinguistics within the structuralist perspective they formed a structured model of narrative which is still being used by the people using narrative as a unit of analysis, they worked on the hypothesis that personal narrative has a basic structure through which a narrative is told orally and the structure is common to all "of ordinary narrative and ordinary speaker". The model is found to be the useful starting point of exploration of identity narrative though it has a limited application in identity negotiation discourses. Labov \& Waletzky's Model of narrative evaluation has been used by Linde (1993) who studied life stories and used this structured model as a starting point (cited in Finna, 2003). She collected data through interviews from a corpus of thirteen white, middle-class Americans to see how they construct their identities through narratives.

The narrative identities can be figured from biographical discourses in which identities are built over time and are revised and rewritten. This gives a polyphonic version of self rather than a monolithic one. Autobiographical narratives do two things, representing and expressing self along with constituting it (Grad \& Rojo, 2008). Besides autobiographies, the other traditions are those of conversational analysis and ethnomethodological for the construction of identity, which also sees identity as emerging in interaction. Thus it is a process, a performance that is not internalized but negotiated within a certain context. In this paradigm members, interaction and their context are important. This leads to the study of categorization process through which people do not have individual identities but they are identified through categories and as having features characterize by that category.

Besides being a research approach narrative is also a unit of analysis that examines the discursive construction of self, this feature of narrative differentiates it from other forms of discourse. Temporal ordering or sequence is quite important in narratives if the events are casually linked even then there is some sequence in the links. The recent development in narratives is that of narrations of personal experience.

In another study, Finna (1999) explored the relation between migration and identity and then the accompanying discourses constructions among the Mexican immigrants in the US. She collected data through sociological interviews of 14 members of the immigrant community. The data was analyzed for "identity" through discourse analytical approach, to find out the linguistic choices in the interactive world of narratives.

Finna (1999) argued that immigrants identify themselves through ethnicity, which they believe to be their main and central identity. Ethnic mention was found to be quite common in the narratives of the Mexicans. Such emphasis on ethnicity also reveals the presentation of behaviours and attributes of in-group in comparison to the out- group, especially in argumentative narratives. The group expectations are also talked about in the individual stories. Such pervasiveness of ethnicity in the narratives of undocumented Mexicans immigrant workers can only be understood in the framework of wider social processes, such as pressures of the ideology of race and ethnicity, which is exerted through the public discourses in American society that have become a part of every individual living in that society.

The identity shaping narratives are formed by the person himself, people around and even by on going social discourses. For instance, the discourses on migration contribute in making of the immigrant identity by effecting the perception of immigrants and other people. It is through these narratives that immigrants try to give meaning to their lives to construct a self that is socially recognizable. Ricoeur (1990) strongly believed in making of identity through narratives and that such narratives have all the elements of narrations such as the plot, characters, situation and most importantly time sequence. "Narration thus mediates between the past, present and future..." (cited in Grad \& Rojo, 2008, p. 11). The person does not have various identities but is engaged in different roles, which together makes his identity. As autobiographies, biographies and narrative show identity as a coherent whole where changes are also shown as a part of it and are smoothly interwoven.

\section{Research Methodology}

The present work is a qualitative analysis of the narratives that are formed through the semi structured private interviews of Urdu Speaking Mohajir/ immigrants in Pakistan. According to Finna (2003) narrative is "particularly apt to become the locus of expression, construction, and enactment of identity" (p. 11). Such a construction of identity through narrative or storytelling is influenced by the teller's personal experiences or the context, thus making certain identities important in situational and interactive context.

\section{Kerby (1991) defines narrative as}

a primary embodiment of our understanding of the world, of experience, and ultimately of ourselves. Narrative employment appears to yield a form of understanding of human experience, both individual and 
collective, that is not amenable to other forms of exposition or analyses (cited in Rapport \& Overing, 2000, p. 283).

The narratives that are analysed for this study are just not the sites of identity construction but also create a relationship between people and society through which they associate their self to the members and the society they are a part of. Narrations or simply call story telling is giving coherence to the fragmented experience (Bakhtin, 1981, Cited in Farrell, 2008). In the context of migration, this becomes important as it often leads to tension between fragmented decentered and shifting identities experience by groups and individuals and their desire for meaning and coherence. According to Farrell (2008) Identity narrators are a unique means of resolving this tension, (re) constructing the links between past present and future and imposing coherence where there was none. Now new narrative and images offer a way to impose imagery coherence on the experience of dispersal and fragmentation, which is the history of all enforced diaspora.

\section{Theoretical Framework}

The present study is underpinned by Finna (2003) work on immigrant discourse, which also acts as the theoretical framework. Finna (2003) gave three levels to study the relationship between narrative and identity. (1). The narrator being a member of a certain community makes choices from the available linguistic and rhetorical resources that project his identity as the narration is reflected of a shared scheme. (2). The second level of identity is related to the negotiation of the social role, which is either confirmed or apposed in narration so that the narrator is supporting, modifying or rejecting these social roles. (3). At another level the narrator depicts categorization of self and other, negotiating such identities, to qualify himself to be the member of a certain group and not of the other group.

\section{Interviews}

The interviews were conducted to form narratives for analysis. Twelve topic related, semi-private interviews were conducted which attempted to determine the views, attitudes, opinions who belonged to the second and third generation of Mohajir/immigrants. The interviews took place in a relaxed environment. Many at participants' workplaces in their free time, some at their homes after an appointment. Such an atmosphere gave the respondent enough opportunity to ponder over the questions and gave their own opinions with any clarification when required since the topic of immigrant identity is a sensitive one, so many of the interviewees got emotional too. The interviews were dialogic in nature, which kept a sequence and continuity in thought and answering. It was made sure that they were least interrupted while they were answering the questions.

The research paradigm for the present study is qualitative; therefore the sample is small but information rich. Also, no claims are being made for a representative one. The data from these interviews is depictive of patterns in individual's expressions of immigrant identity. The discourse produced through these interviews illustrates the subjective dimension of construction of immigrant identity. It also traces the reception of public discourses and the diffusion of particular notions about the immigrant identity from legal discourses to media and down to the subjective opinions of the people. Holz (1994) declares topic related interviews the most suitable for collecting "subjective views of interviewees on socially relevant area". (Cited in Wodak et al., 2009 p. 147)

Few pilot interviews were conducted so as to improve the quality of the interview questions. After changing, adding and deleting some questions, ten intensive interviews were done, each lasting between 30 minutes to 1 hour 10 minutes. The interview protocol was followed thoroughly. The purpose and objectives of the interviews were explained to the participants and their queries were answered. They were given the consent form and interviews were recorded only when the participants were fully satisfied and showed complete willingness for participation. The interviews went smooth and people participated enthusiastically. Almost all of them allowed recordings but some them requested anonymity afterward. For the same reasons of confidentiality the interviewees are presented and referred to in the analysis by their number + gender, for instance, $1 \mathrm{M}$ refers to interviewee 1 male. The names of the participants are not mentioned in any part of this work.

The interviews were recorded and transcribed in their entirety. By language use, the interviews were of three kinds. Some were completely in English, few participants felt more expressive and at ease in Urdu but most of the interviews were a combination of Urdu and English. The three kinds were differently dealt during transcription. The interviews that were in English were transcribed as they were, the ones in Urdu were also transcribed first in their entirety in roman Urdu but then they were translated into English for analysis. The last kind of interviews that were both in English and Urdu were transcribed and the parts containing Urdu were translated into English. Moreover, word-to-word translation was not the focus but the translation was done to get the meaning and expression with its true essence. 


\section{Description of the Sample/Participants}

The sample consisted of 12 participants, 6 males and 6 females. Their age ranged from 25 years to 70 years. Only one was a second-generation immigrant, who was born in India and travelled to Pakistan as a child with his parents at the time of creation of Pakistan in 1947. The rest of them were from the third generation who were born and brought up in Pakistan. All of the participants were educated and belonged to a middle class, as the Urdu Speaking Mohajirs are popularly defined. Five out of twelve were doctors, two medical doctors, three Ph.D doctors, three lecturers, one government servant, one engineer and two businessmen. By and large parents or grandparents of all these interviewees hailed from the province of UP in India from cities like Lucknow and villages like Saswan, with the exception of one whose parents migrated from Ludiyana, a place in Indian Punjab.

\section{Data Analysis}

The first question, "Who are Mohajir/immigrants in Pakistan"? was asked to see the diffusion of public discourses and the linguistic construction of common immigrant identity-related notions. The analysis of all the answers to this question indicates that most of the participants agreed that Mohajir in Pakistan still refers to the people who migrated from India at the time of partition/ independence in 1947 and for a few following years and their generations who were born and grew up in Pakistan. Most of them also agreed that the term is now limited to the generations of those immigrants of 1947 whose mother tongue was Urdu and majority of them settled in urban parts of Sindh but they are living in all provinces of Pakistan. Few had a different definition/conception about immigrants/Mohajirs as $2 \mathrm{M}$ replied

Mohajirs are not only Urdu Speaking but also all those who came to Pakistan from India for a Muslim country. I migrated with my parents from Etawa (UP, India) and when I used to hear this term Mohajir, I would ask my father and he would reply that no one was an immigrant or a Mohajir and everyone was a Pakistani ... as I already said, it was not only Urdu Speaking's who were immigrants, Punjabis were also in large number who migrated from East Punjab to West Punjab, from areas like Ludyana, Haryana, Amritsar etc. Sindhis came from Bombay and Hindu Sindhis went to India. But the case of these two communities was different from that of Urdu Speakings. These two communities had their own provinces with the same language and culture so they assimilated and the tag of Mohajir shed off for them, therefore. But when Urdu Speaking came here they had no support in the new land, they had no land of their own. There were no people with a similar language and culture. From the very beginning the word Mohajir was not appreciated (4M).

Participant $4 \mathrm{M}$ was the oldest of the interviewees, around 70 years old. He believed that Mohajir word was never favored from the very beginning and that among all the immigrants the word got confined to Urdu Speakings because they were different from the rest of the population with their failure to assimilate.

Another kind of Mohajir entered the linguistic repertoire of Pakistan with the Soviet war in Afghanistan and a huge influx of Afghanis in Pakistan and they were called as "Afghan Mohajireen" as one of the interviewees indicated and said

There are two kinds of Mohajirs in Pakistan, when we speak in Quetta we are referring to Afghan Mohajirs but when people in other parts of Pakistan refer them they are usually the Urdu Speakings residing in the province of Sindh $(1 \mathrm{M})$.

So the notion in discourse has different connotation and associations according to the regions in which they are being used. As Quetta received the most immigrants from Afghanistan, the term was more frequently used for them and also because Urdu Speakings are in a very small minority in Balochistan as opposed to the situation in other parts of Pakistan specifically in Sindh where Urdu speaking form a sizable majority in its urban centers. All participants from Karachi showed a straightforward association of the term Mohajir with "those Muslims and their descendants of different ethnic origin who migrated from different regions of India and settled in Pakistan after the partition of India in 1947" (3F). But there were participants who refused to go with the established discursive practices around the association with the word Mohajir as one of them speaking emotionally said

We are the builders of Pakistan. As a matter of fact, no body by definition was a Pakistani before its creation. All were Indians. The now called locals were not Pakistanis; there was no Pakistan so Pakistan was made by us $(5 \mathrm{~F})$.

The above reply shows the defiance of the popular identity term Mohajir used for a group of people and it so seems to be against their will. A participant calls such a situation as ironic and says, "It is because of us that people gained here Pakistani identity and ironically they became Pakistanis and we are still Mohajirs that is why the term is quite disturbing." Another participant stating an identity-related fact about immigrant said "Mohajirs are people who could not assimilate into the culture of Pakistan because of their different language and the 
culture that they clung to." (3F). So it was just not a matter of ongoing discourses or the formulation of discursive practices with these discourses that reconstructed and perpetuated immigrant identity for Urdu Speaking people but it was their failure to assimilate into the local culture and keeping their language and culture intact. They did not feel the need to learn the local languages because their own language had an acceptance and recognition even before Pakistan and was immediately declared as the national language of Pakistan. One of the interviewees also opined that he was not a Mohajir or an immigrant because he never migrated from another country, his parents might have but he was completely a Pakistani citizen. People gave a little-varied perception as to "Who are Mohajir in Pakistan?" but most of them agreed that the term is popularly and discursively used in the media and elsewhere for people and their descendants, who migrated from Muslim minority provinces of India, spoke Urdu and settled in urban parts of Sindh. One participant also said that their majority might be in Sindh but "they are residing in every nook and corner of the country, but with the passage of time everybody is trying to migrate to Karachi generation after generation, where they feel more at home." (1M). The participant also told that whenever they are troubled in other parts of the country, they try to move to Karachi because they consider it the only place for them, being in a considerable majority in the mega city. This participant gave the example of recent Baloch struggle in Balochistan, many nonlocals (as Mohajirs are called here along with Punjabis) were forced out of their homes from the interior of the province, and most of those who spoke Urdu chose Karachi to be their destination for safety. Many Urdu Speaking government servants move to Karachi after retirement.

Most participants in the interview did not prefer any ethnic identity when asked their usual reply to the everyday question "who are you?" with an understanding that when this question is asked in Pakistan it aims to inquire about the ethnicity and not about religion or national identity. An interviewee agreed that such discourses about ethnicity "do not allow us to become the part of the province and the country we are living in, while the other ethnicities are immediately recognized. So this situation is disturbing." (2F) She informed that her reply to the common identity question is "I am a Pakistani, then I would say I am an Urdu Speaking and after that, they would say are you from Karachi?" (2F).

Immigrants/Mohajir/Urdu Speaking lack the much-needed ethnic identity and the query about their identity put them in an awkward situation because saying someone is a Muslim or a Pakistani are not the satisfactory answers, as one of the interviewees replied

But of course people over here are very much prejudiced and it sometimes gives me an awkward feeling of not more than just Pakistani and a Muslim but I am here and I was born here and I got my education over here. I am a Pakistani, I don't need another identity (1F).

The argument goes on where Mohajirs struggle to become the people of the land but the popular discursive practices will not let them because the simple use of the word Mohajir adds an element of transience, people, who do not belong here and just came to live for some time. One participant on identity question replied "I do not call myself Mohajir now. I usually say that I am Urdu Speaking because Urdu Speaking is also taken as Mohajir but it was my grandparents who migrated and not me" (3F). The term Mohajir has not remained acceptable to many members of the community as one interviewee said "I call myself a Pakistani, I am Pakistani forever and if I tell you by heart, I don't like to be called a Mohajir I like to be called Urdu speaking" (3M). Another participant replied,

I try to avoid the term Muhajir. I prefer usually that I am Urdu Speaking. Sometimes people here in Balochistan, who don't have exposure consider Urdu Speaking as Punjabi so they put us in the category of Punjabi but I prefer to belong to Karachi if I need to explain about me or about Urdu speaking like when my maid asks me that who am I then I say Urdu Speaking like the people of Karachi (4F).

Urdu speaking immigrants consider Karachi as their own city as they form a majority wherever an explanation of their identity is needed; they prefer to refer to Karachi and no other place in Pakistan. Karachi is an identity reference place for them.

A second-generation immigrant felt himself out of available identity option when a question about his identity is asked as he says "In school when I was asked "who are you?" I was none from the available presented options of Pathan, Baloch, Bravi, Punjabi, Sindhi, so I had to say Mohajir and the teacher would say "what is Mohajir? Hindustani?" The narrated event was the practice in the 1950s almost 60 years ago that shows that there was not an acceptance of such an identity. The interviewee continued

My reply to the identity question as being Pakistani remained unsatisfactory and I was further questioned about my place and then the question about the place my father migrated from. I did not have the answer to the question "who are you?" in my childhood nor do I have it now after more than half a century. There is 
another English word for Mohajir which is "settler" but that is also a negative one. The question is really problematic $(4 \mathrm{M})$.

Choosing a proper identity term has always remained problematic and challenging for the "Mohajir" community in Pakistan. They try to justify having linguistic identity as one of the participant noted: "we are Urdu Speaking like there are Pashto Speaking, Sindhi Speaking" (5F). According to this version Urdu Speaking or Mohajir do fit in well in the diverse linguistic canvass of Pakistan, because they are also the speakers of a distinct language like the rest of Pakistanis. But the fact remains that they are the only group of people who need to explain their identity and still in search of a proper name for it.

The data from the interviews showed that there is less acceptability for the term Mohajir. On inquiry "How do you feel about the identity terms Mohajir and Urdu Speaking" many replied that the word itself is distancing and alienating with an associated expression of otherness and not being a part of the group, as an interviewee sadly expressed

I have suffered from this inferiority complex throughout my life. Whatever term is used it signifies that you do not belong to this land, to these people, you do not share their sorrows and happiness, you are not needed here. You are a burden on them. Whatever term you use. I have not found a satisfactory term among all the terms that I have heard over the last 46 years of my life (1M).

The term is used with some ulterior motives said another third generation participant

This word serves the purpose of marginalization. When they call someone Mohajir it implies that the person is not from among us and he is not supposed to avail all the opportunities and chances that the natives or the locals can. It informs that the person is an outsider. I don't feel good about the word Mohajir and people using it particularly for me because I don't think myself a Mohajir or somebody outside this country, I am a part of this country I would like to be called a Pakistani (1F).

The discursive practices in this particular case re-constructing an unwanted identity, that is making its bearer insecure even after generations. One interviewee expressed "I feel bad as such a discourse does not allow us to become the part of place we are living in while other ethnicities have acceptable identities which are recognized" (2F). Many interviewees agreed that the word Mohajir no longer has a positive connotation and implicitly indicative of a term for those who are identity deficient. It almost has become an abusive term and many times use to "annoy people", informed another participant, who added, "they wanted to call us Mohajir, they wanted to see us Mohajir, we are not Mohajir" (3M). This opinion gives intentionality to the immigrant discourse that people use the term with the intention of reminding the people of their temporary existence in the country. But alongside the majority who believes the term to be derogatory, there were participants who associate the term with the Islamic history and feel honored to be called Mohajir, as the youngest participant, a medical student in Karachi informed,

The word Mohajir has a great Islamic history. It is associated with the hundreds of Muslims who migrated from Makkah to Madina, so with this background one must feel that it is one of our holy Prophet (SAW) sunnah. With this reference, I am not ashamed of it and I proudly call myself as Mohajir (6F).

One of the interviewees also said that the connotation and association with the term Mohajir have not always been a negative one but has come to gain negativity over the years, from the time of independence 1947 to now, "I think at that time people were so much proud to be Mohajir but now for me I am not very much comfortable" (4F). A second generation elderly Mohajir/Urdu Speaking put this historical changes in the following words

The term Mohajir was firstly used by Mohajir himself following the sacred migration of the prophet (PBUH), so the word gained respect in that particular context but later it was a word used with hatred. Then we avoided calling ourselves Mohajir (4M).

The alternative euphemistic term that most of the interviewees agreed to was Urdu Speaking as one gave her last option as "I feel very bad about the term Mohajir, Urdu Speaking is a better one. But we do not have any identity other than that, we do not have any land, so we cannot say we are Sindhi" (5F). Loss of identity and a search for it was noticeable in their expression and in their voice during most of the interviews. They seem to have found an escape in the term Mohajir when so many other derogatory address terms started to become a part of everyday discourse. Their last refuge was calling themselves Urdu Speaking, as an elderly interviewee recalled,

I was always called Hindustani and several other terms. To escape from all the negative words, we fell back on the term Mohajir. This Urdu speaking term started to be used after the language bill of 1972 when the bill was interpreted to be against Urdu language, it was at this time that Urdu Speaking community came to the fore and not all immigrants/ Mohajirs who migrated from India. So initially Mohajir was used for 
people of various communities but later on those were restricted to Urdu Speaking" (4M).

The interpretation of any kind of discourse is not only context dependent but also depends on discursive practices, which frames its interpretation. This is the reason for the changing connotation of the word Muhajir over the years from positive to negative and the people from acceptable to unacceptable. The negativity that got attached to this community and its members has political reasons and the way they were politically introduced in the country through a political party who claimed to represent the whole group despite the fact that many of the Urdu-speaking Muhajir/immigrant do not support their party, its leadership, and its activities. The discursive practices surrounding the Mohajir/immigrant identity let to the stereotypical conception that everyone whose mother tongue is Urdu is a supporter and voter of one single political party. The next interview question was to confirm such a stereotypical thinking, which has become a part of immigrant/Mohajir identity due to the ongoing discourses and discursive practices. The question that was put to the participants was "Do people associate you with a single political party regardless of your choice?" Most of the respondents agreed that as soon as anyone comes to know about their linguistic identity their political association is instantly made with MQM (Mohajir/Motahidda Quomi Movement). The following interviewees' replies elaborate the same "People think that everyone who speaks Urdu should be associated with this party. And no other reason and that is very natural. Most of the parties are ethnic parties" (1M). Many people do not own their political representative or at least do not do it openly as one interviewee remarked, "ya they do. It is their presupposition that I am a supporter of MQM. They think that definitely, we belong to MQM. But no such thing exists. I don't own MQM" (2F). Sometimes in a serious manner and at other times jokingly such an assumption remains a part of everyday discourses. Urdu Speaking in such situations feel that their identity is being targeted. In reply to the above question one participant, a Ph.D. doctor replied, "sometimes they jokingly say oh you are from MQM It happens and then I feel pretty bad that they associate us with MQM. They just target your identity that you are a Mohajir. And I feel very uncomfortable about the situation" (2F). Such a strong perception, in turn, means "they associate us with terrorism and violence" (2F). Such a thinking has some good reasons behind as put by a participant "they think that whosoever is a Mohajir belongs to a single political party because the party made for Mohajir and it remains a fact that many people joined the party because it was a Mohajir party and they were Mohajirs" (3F). Some of the participants confessed their earlier days affiliation with the party "I was a member of MQM but completely dislike it now since the notorious fact about it surfaced" (3M). Another said "ya they do, saying "Ok you are from MQM though I am no more associated with it now, years back I did participate in its campaigns". Associating Mohajir with MQM has remained a common practice and prevalent discursive practices have added it to the identity of Urdu Speaking. The association between the party and the people might be more common in Karachi, since the party is considered to be Karachi-based but the interview data from other cities like Quetta shows the same assumption on the part of people as answered by a participant

yes, they do. Now as my social circle is widening so I feel that this is not only in Karachi but it is everywhere, I have heard this term MQM walay (from MQM) as people say you are from MQM and I say ya I am from MQM (4F).

From the semi-private data, a consensus can be seen about a widely spread perception that anyone who identifies himself/herself as Mohajir is labeled as MQM supporter. From this political labeling, the interview moved to what do the members of immigrant community feel about their identity as a Mohajir so the question "What does being a Mohajir mean to you?" there had been a feeling of otherness, being unwanted and not needed as one of the interviewees replied "being a Mohajir means being an outsider in this country, it means a spy for India, it means a man who has usurped others' seats and resources, it means a man who is not wanted" $(1 \mathrm{M})$. Another remarked "feeling of displacement leaving everything behind and not getting a warm welcome. So being a Mohajir is a struggle in other words" $(1 \mathrm{~F})$. A positive feeling about self-identity was found lacking in the participants, as one of them felt it to be a tabooed identity now, which initially was not the case. The negative political representation has remained such that "what they associate us with is terrorism and violence" (2F) said a participant. Still, there are Mohajirs/Urdu Speaking who clung to the particular definition of Mohajir Urdu Speaking as "educated, qualified and respectable" (3F). The topos of definition has been used in a number of discourses where they are defined as an educated, cultured and middle class. Their identity started with these defining features and characteristics because the people who migrated from India to Pakistan were mostly from educated and middle class salaried people. Mohajir identity is also taken positively by those who connect it to the historic migration in the Islamic history as one aptly remarked: "being a Mohajir for me means an act that my Prophet (SAW) has done fourteen hundred years ago so for me it is a noble act" (3F). The religious association with the identity term has politically been highlighted in a number of discourses one such has been analyzed in this work also. Some of the participants refused to be called or be considered as Mohajirs because they believe 
that they never migrated to any place, it was their parents or their grandparents who migrated and came to be called as Mohajirs/immigrants, while they are an equal citizen of this country. Being a Mohajir/immigrant means a life long struggle for identity, as said by a respondent "we are still fighting to get an identity, because of our forefathers and our parents who were over here, they spent their whole life but could not get an identity. We are still treated as other" (1F), "when someone calls you Mohajir it means you are an outsider not a part of the place, the city, province or the country" (2F). The transience and the otherness that is attached with the word Mohajir get transferred to the bearer of this identity and people can be made to feel other when addressed with such an identity term, or they identify themselves as one. So being a Mohajir or an immigrant means a state of identitylessness and a perpetual strife for an identity.

\section{Conclusion}

The data is suggestive of the fact that Mohajir/immigrant is not a much-desired identity for its bearers. The identity is linguistically constructed with this term having political undertones and most of the participants defined it in a similar way. The members also believe that they are a distinctly separate group or an ethnic community because they feel themselves linguistically and culturally different from the rest of the ethnicities in the country. This also suggests their failure of much-needed assimilation. The notion of us and them was also found in the interview data for instance in the cited interview lines such as "we are builders of Pakistan ... and calling us Mohajir. They were not Pakistanis, there was no Pakistan. We are still Mohajir." The participants were of the view that such discursive terms are exclusionary and discriminatory. Politics was seen to be a major element in the transformation and reconstruction of immigrant identity, making it an undesired one, which was not the case decades ago.

\section{References}

Alaxander, J. C. (2006). The civil sphere. Oxford: Oxford University Press.

Baig, N. (2005). From mohallah to mainstream: The MQM's transformation from an ethnic to a catch-all party (Master's Thesis). University of Victoria.

Baker, P., Cabrieltos, C., KhosravNik, M., Krzyzanowski, M., McEnery, T., \& Wodak, R. (2008). A useful methodological synergy? Combining critical discourse analysis and Corpus Linguistics to examine discourses of refugees and asylum seekers in the UK press. Discourse \& Society, 19(3), 273-306; 29(1), 34-44. https://doi.org/10.1177/0957926508088962

Davies, B. (1990). Agency as a form of discursive practice. A classroom scene observed. British Journal of Sociology of Education, 11(3), 341-361. https://doi.org/10.1080/0142569900110306

Farrell, E. L. (2008). Negotiating identity: Discourses of migration and belonging. Macquarie.

Findlay, A. M., \& Li, F. (1997). An autobiographical approach to understanding migration: the case of Hong Kong emigrants: The Royal Geographical Society, 29(1), 34-44.

Finna, A. D. (1999). Immigrant identities: A discourse analysis of narrative told by Mexicans in the US. Oregon State University.

Finna, A. D. (2000). Orientation of immigrant narratives: The role of ethnicity in the identification of characters. Discourse Studies, 2, 131-157. https://doi.org/10.1177/1461445600002002001

Finna, A. D. (2003). Identity in narratives. Amsterderm: John Benjamins Publication. https://doi.org/10.1075/sin.3

Grad, H., \& Rojo, L. M. (2008) Identities in discourse. In R. Dolon \& J. Todoli (Eds.), Analysing identities in discourse (pp. 3-28). Amsterdam/Philadelphia: John Benjamin Publishing Company.

Howard, J. A. (2000). Social Psychology of Identities. Annual Review of Sociology, 26, 367-393. https://doi.org/10.1146/annurev.soc.26.1.367

Koegan, K. (2000). A sense of place: The politics of immigration and the symbolic construction of identity in Southern California and the New York Metropolitan area. Sociological Forum, 17(2), 223-253. https://doi.org/10.1023/A:1016037213134

Mohajir. (1998). In Ferozson Urdu English Dictionary. Lahore: Ferozsons (Pvt.)

Poznaik, K. (2009). Talking the "Immigrant Talk": Immigration narratives and the identity construction among Columbians newcomers. Canadian Ethnic studies, 41(1), 173-190. https://doi.org/10.1353/ces.2009.0001

Raza, H. (2005). Unraveling sharam as a metaphor for Mohajir identity in Salam Rushdi's Shame. SOAS 
Literary Review, (4). Review from http://www.soas.ac.uk/soaslit/Issue4a/raza.pdf

Refugee Review Tribunal Australia. RRT Research Response. (2008). Retrieved from http://www.refworld.org/pdfid/4b6fe2dd0.pdf

Schiffrin, D. (1996). Narrative as self-portrait: Sociolinguistic constructions of identity. Language in Society, 25(02), 167. http://dx.doi.org/10.1017/s0047404500020601

Silvey, R., \& Lawson, V. (1999). Placing the Migrants. Annals of Association of American Geographers, 89(1), 121-132. https://doi.org/10.1111/0004-5608.00134

Sjorbery, U., \& Rydin, I. (2008). Discourses on media portrayal of Immigrants and the Homeland. Paper presented at ECREA's 2nd European Communication Conference. Barcelona: Halmstad University.

Tajfel, H. (1981) Human groups and social categories: Studies in social psychology. Cambridge, England: Cambridge University Press.

Verkaaik, O. (2005). Migrants and militants. New Delhi, India: Manas Publications.

Weldenyesus, W. M. (2007). Narrative and identity construction among Ethopian Immigrants. University of Colarado.

Wodak, R., Cillai, R., Resigl, M., \& Liebhart, K. (2009). The discursive construction of national identity. Edinburgh: Edinburgh University Press.

\section{Copyrights}

Copyright for this article is retained by the author(s), with first publication rights granted to the journal.

This is an open-access article distributed under the terms and conditions of the Creative Commons Attribution license (http://creativecommons.org/licenses/by/4.0/). 